cardiovascular, were common. Compared to patients treated with TNFi, UST was more often given as 2nd or 3rd line bDMARD and in patients with more axial and skin disease. Among patients who switched to a 2nd or 3rd line bDMARD, those not on concomitant csDMARDs preferentially received UST.

Acknowledgements: This study was sponsored by Janssen.

Disclosure of Interest: L. Gossec Grant/research support from: Pfizer, Consultant for: AbbVie, Celgene, Janssen, Lilly, Novartis-Sandoz, Pfizer, Sanofi, and UCB, P. Athanassiou: None declared, P. Bergmans Shareholder of: Johnson and Johnson, Employee of: Janssen, K. de Vlam Consultant for: Johnson and Johnson, E. Gremese Consultant for: AbbVie, Janssen, Lilly, Pfizer, Speakers bureau: AbbVie, Janssen, Lilly, Pfizer, B. Joven-lbáñez Speakers bureau: Celgene, Novartis, MSD, Pfizer, AbbVie, and Janssen, T. Korotaeva Consultant for: Pfizer, MSD, Novartis, AbbVie, Celgene, Biocad, Janssen, and UCB, Speakers bureau: Pfizer, MSD, Novartis, AbbVie, Celgene, Biocad, Janssen, and UCB, F. Lioté Grant/research support from: Principal investigator or Co-PI for Janssen, MSD, Pfizer, Novartis, AbbVie, and Celgene, Consultant for: Advisory boards for Celgene and MSD, M. Nurmohamed Grant/research support from: Received research support to his institution from Pfizer, AbbVie, Roche, BMS, MSD, Mundipharma, UCB, Janssen, Menarini, Eli Lilly, Sanofi, and Celgene, Consultant for: Pfizer, AbbVie, Roche, BMS, MSD, Mundipharma, UCB, Janssen, Menarini, Eli Lilly, Sanofi, and Celgene, Speakers bureau: Pfizer, AbbVie, Roche, BMS, MSD, Mundipharma, UCB, Janssen, Menarini, Eli Lilly, Sanofi, and Celgene, P. Sfikakis: None declared, S. Siebert Grant/research support from: Receipt of grants/ research support to his institution from Pfizer, Janssen, BMS, Celgene, UCB, and Boehringer Ingelheim. participation in clinical trials with AbbVie, Novartis, and UCB, Consultant for: AbbVie, UCB, Pfizer, Janssen, Boehringer Ingelheim, Celgene, and Novartis, Speakers bureau: AbbVie, UCB, Pfizer, Janssen, Boehringer Ingelheim, Celgene, and Novartis, P. Smirnov Employee of: Janssen, E. Theander Employee of: Janssen, J. Smolen Grant/research support from: Received grants for his institution from AbbVie, Janssen, Lilly, MSD, Pfizer, and Roche, Speakers bureau: Provided expert advice to and/or had speaking engagements with AbbVie, Amgen, Astra-Zeneca, Astro, Celgene, Celtrion, GlaxoSmithKline, ILTOO, Janssen, Lilly, Medimmune, MSD, Novartis-Sandoz, Pfizer, Roche, Samsung, Sanofi, and UCB

DOI: 10.1136/annrheumdis-2018-eular.5512

\section{SAT0338 PREDICTION OF CARDIOVASCULAR EVENTS IN PATIENTS WITH PSORIATIC ARTHRITIS: PERFORMANCE OF FIVE RISK ALGORITHMS IN AN ITALIAN BICENTRIC STUDY}

L. Navarini ${ }^{1}$, D.P.E. Margiotta ${ }^{1}$, F. Caso ${ }^{2}$, D. Currado ${ }^{1}$, M. Tasso ${ }^{2}$, S. Angeletti ${ }^{3}$, M. Ciccozzi ${ }^{3}$, R. Scarpa ${ }^{2}$, A. Afeltra ${ }^{1}$, L. Costa ${ }^{2}$. ${ }^{1}$ Unit of Allergology, Immunology, Rheumatology, Department of Medicine, Università Campus Bio-Medico, Rome; ${ }^{2}$ Rheumatology Unit, Department of Clinical Medicine and Surgery, University Federico II, Neaples; ${ }^{3}$ Unit of Clinical Laboratory Science, Department of Medicine, Università Campus Bio-Medico, Rome, Italy

Background: The burden of cardiovascular (CV) risk in patients with psoriatic arthritis $(\mathrm{PsA})$ is increased. Prediction of $\mathrm{CV}$ risk and consequent preventive strategies play a pivotal role in management of PsA. Recently, EULAR recommendations suggested to use a multiplication by the factor of 1.5 of original CV risk algorithms in patients with rheumatoid arthritis and other inflammatory arthritis. ${ }^{1}$ Objectives: To evaluate the performance and calibration of five original and adapted according to EULAR recommendations CV risk algorithms in PSA: SCORE, CUORE, Framingham Risk Score (FRS), QRISK2, and Reynold's Risk Score (RRS).

Methods: Prospectively collected data from two Central-Southern Italian cohorts of patients with an history of PsA of almost 10 years at November 2017 and without a personal history of CV disease (CVD) at baseline has been used. The primary outcome was the first CV event: sudden cardiac death, coronary artery diseases (CAD) (stable and unstable angina pectoris, myocardial infarction), cerebral vascular accident (CVA), transient ischaemic attack (TIA), peripheral artery disease (PAD) and heart failure (HF). Discriminatory ability for CV risk prediction was evaluated by the area under the receiver operating curve (ROC). Calibration between predicted risk and observed events was assessed by Hosmer-Lemeshow $(\mathrm{HL})$ tests and calibration plots. Fisher's exact test has been used for analysis of contingency table 1, while Mann-Whitney test has been used to compare ranks. Sensibility, specificity, and odds ratio were calculated for low-to-intermediate risk cut-off ( $1 \%$ for SCORE, $10 \%$ for all the other algorithms) and for intermediate-to-high risk cut-off ( $5 \%$ for SCORE, $20 \%$ for all the other algorithms).

Results: 155 patients $(57 \pm 10.57$ years) were enrolled with an observation of 1550 patient/year. During follow-up, 21 patients had a CV event ( 1.35 events per 100 patient/years): 8 cases of myocardial infarction or unstable angina pectoris, 3 cases of stable angina pectoris, 2 cases of TIA, 4 cases of PAD, 4 cases of HF. No fatal events were reported. Area under the ROC were 0.7679 (95\% Cl 0.64768 to 0.88812$), 0.864(95 \% \mathrm{Cl} 0.79675$ to 0.93278$), 0.7575(95 \% \mathrm{Cl} 0.65784$ to
$0.85708), 0.8660$ (95\% Cl 0.79428 to 0.93772 ), and 0.7183 (95\% Cl 0.57795 to 0.85862 ) for SCORE, CUORE, FRS, QRSIK2, and RRS, respectively, suggesting fair to good discriminative ability between patients with or without a CV event (fig ure 1). $\mathrm{HL}$ tests demonstrated poor model fit $(\mathrm{p}<0.05)$ for SCORE, CUORE, and RRS, but not for FRS and QRISK2 ( $>>0.05)$. Discriminative ability and calibration were not improved by adaption of the algorithms according to EULAR indications. A large amount of patients who experienced a CV event was at "low risk" (minimum $17.6 \%$ for SCORE and maximum $81.8 \%$ for RRS) or at "low-intermediate" risk (minimum $52.9 \%$ for SCORE and maximum $95.2 \%$ for FRS).

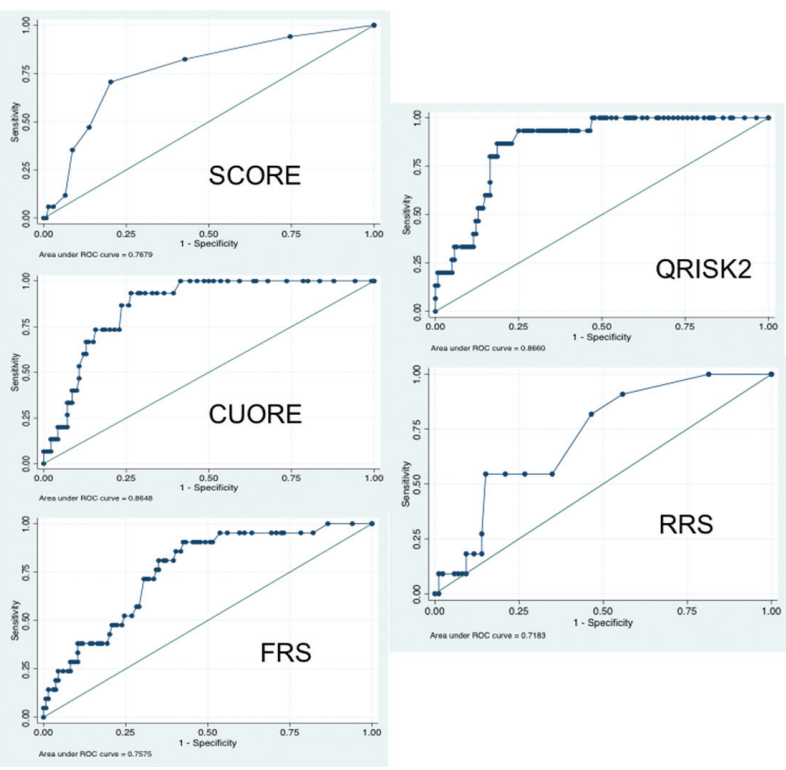

Conclusions: Adaption of the CV risk algorithms according to EULAR indications did not provide improvement in discriminative ability and calibration in patients with PsA from Centre and South of Italy. In PsA, an excess of CV events has been observed in patients at "low risk" or "low-intermediate risk".

REFERENCE

[1] Agca R. et al. Ann Rheum Dis 2017;76:17-28.

Disclosure of Interest: None declared

DOI: 10.1136/annrheumdis-2018-eular.7169

\begin{tabular}{|l|l}
\hline SAT0339 & IMPACT OF ALTERNATE MECHANISM OF ACTION \\
& BIOLOGICS ON TUMOUR NECROSIS FACTOR \\
& INHIBITOR (TNF) PRESCRIBING IN PSORIATIC \\
& ARTHRITIS: RESULTS FROM A NATIONAL PATIENT \\
& CHART AUDIT
\end{tabular}

J. Robinson, L. Price. Advanced Analytics Group, Spherix Global Insights, Exton, USA

Background: Tumour Necrosis Factor-inhibitor (TNF) therapy has long been the standard of care for adult patients diagnosed with moderate to severe psoriatic arthritis (PSA), though several new biologics and small molecules have recently received FDA approval for the treatment of PsA.

Objectives: This research sought to understand the extent to which biologics and small molecules with a different mechanism of action (MOA) have been adopted for the treatment of PSA and their impact on the use of well-established TNFs in the United States.

Methods: We conducted a retrospective chart review of patients diagnosed with PsA $(n=1,008)$, who had switched from one biologic therapy or apremilast to another in the prior twelve weeks. Data were collected in April 2017 and included clinical and non-clinical patient demographics, as well as physician demographics and attitudinal survey responses. This study was a non-longitudinal trending analysis to a 2016 audit following the same methodology.

Results: $78 \%$ of the participating rheumatologists reported recent changes to the management of their patients with PsA. The two most commonly recalled treatment shifts were: more aggressive use of biologics in general and an increased use non-TNF agents for the treatment of PsA. With increased treatment options, US rheumatologists are switching patients more frequently and faster than previously recorded. In 2017, US rheumatologists reported that, over the course of a year, $29 \%$ of their biologic and apremilast treated patients are switched to a 
different brand, a figure significantly up from 2016 (25\%). Furthermore, a higher percent of the audited switched patients occurred within six months of initiating the prior agent compared to the prior year ( $56 \%$ vs. $40 \%$.)

In 2017, switching between TNF agents significantly decreased from 52\% in 2016 to $41 \%$ in 2017 , and switches from a TNF to an alternate MOA biologic significantly increased from $13 \%$ to $20 \%$, respectively. The growth in the switching share of alternative MOAs was driven primarily by increased use of secukinumab, an Interleukin-17 inhibitor approved in January 2016. While most of the secukinumab patients originated from TNF inhibitors, ustekinumab switching share was also impacted. Indeed, rheumatologists indicated that $33 \%$ of the patients switched to secukinumab in 2017 would have been placed on ustekinumab if secukinumab had not been available.

Conclusions: Increased biologic and small molecule options for the treatment of PsA has resulted in US rheumatologists switching patients more frequently and faster than in the past. Though TNF inhibitors remain the predominant mechanism of action for the treatment of PsA, the introduction of secukinumab has had a direct impact on the PsA switching environment in 2017 and recent approvals in the form of tofacitinib, ixekizumab, and abatacept are hypothesised to further impact the PsA switching environment in 2018.

\section{REFERENCE:}

[1] RealWorld DynamixTM: Biologic and Apremilast Switching in Psoriatic Arthritis 2017.

Disclosure of Interest: None declared

DOI: 10.1136/annrheumdis-2018-eular.7334
Abstract - Figure 1. [A] Correlation between clinical variables and PsA-Disk score in PsA+ patients.

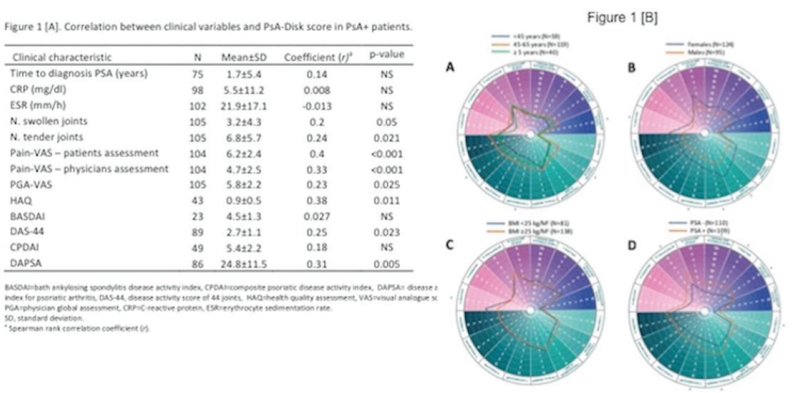

Conclusions: PsA-Disk is a novel instrument helping both dermatologist and rheumatologist in the rapid assessment PsA, facilitating in the timely therapeutic management of these patients.

Disclosure of Interest: None declared

DOI: 10.1136/annrheumdis-2018-eular.3803

\section{SAT0341 EFFICACY AND SAFETY OF IXEKIZUMAB IN PATIENTS WITH ACTIVE PSORIATIC ARTHRITIS AND PREVIOUS INADEQUATE RESPONSE TO TNF INHIBITORS: 52 WEEK RESULTS FROM A PHASE 3 STUDY}

M.C. Genovese ${ }^{1}$, B. Combe ${ }^{2}$, J. Kremer ${ }^{3}$, D. Adams ${ }^{4}$, C. Lee ${ }^{4}$, L. Kerr ${ }^{4}$, P. Nash ${ }^{5}$ ${ }^{1}$ Stanford University Medical Center, Palo Alto, USA; ${ }^{2}$ Department of Rheumatology, CHU Montpellier and Montpellier University, Montpellier, France; ${ }^{3}$ Albany Medical College and The Center for Rheumatology, Albany, ${ }^{4}$ Eli Lilly and Company, Indianapolis, USA; ${ }^{5}$ University of Queensland, Brisbane, Australia

Background: Ixekizumab (IXE) is a high affinity monoclonal antibody that selectively targets interleukin-17A. In patients with active psoriatic arthritis (PsA) who had an inadequate response to tumour necrosis factor inhibitors (TNFi), IXE was superior to placebo (PBO) in improving the signs and symptoms of PsA after 24 weeks of treatment (SPIRIT-P2; NCT02349295). ${ }^{1}$

Objectives: The objective of this study is to report the Week 52 interim efficacy and safety findings of IXE treatment during the Extension Period (EP) of SPIRITP2 (Weeks 24-156).

Methods: SPIRIT-P2 is a Phase 3, multicenter, double-blind study. All 363 patients had an inadequate response to one or two TNFi or were intolerant to TNFi. During the Double-Blind Treatment Period (DBTP; Weeks 0-24), patients were randomly assigned $1: 1: 1$ to subcutaneous administration of either $80 \mathrm{mg}$ IXE every 4 weeks (Q4W; $n=122$ ) or every 2 weeks (Q2W; $n=123$ ) following a $160 \mathrm{mg}$ starting dose at Week 0 , or PBO $(n=118)$. Of these, 310 patients completed the DBTP and entered the EP (Weeks 24-156). Patients randomised to IXE at Week 0 continued the same dose regimen in the EP. PBO patients were rerandomised (1:1) to IXE Q4W or Q2W at Week 16 (inadequate responders) or 24 In this interim analysis, efficacy (up to Week 52) and safety (up to Week 156) were analysed using the EP population, defined as all patients who received at least 1 dose of study drug in the EP. Missing values were considered non-response for categorical data and were imputed by modified baseline observation carried forward for continuous data.

Results: In the DBTP, a significantly higher percentage of patients achieved ACR20 at Week 24 with IXE Q4W (53\%) or Q2W (48\%) than with PBO $(20 \%)$. For patients who entered the EP, the mean age was 52 years, $47 \%$ were male, the mean time since PsA onset was 12 years, and mean tender and swollen join counts at baseline (Week 0 ) were 23 and 12, respectively. For EP patients who were initially randomised to IXE Q4W or Q2W during the DBTP, ACR20 responses at Week 52 were $68 \%$ and $59 \%$, respectively. For patients treated with PBO during the DBTP and re-randomised to IXE Q4W or Q2W during the EP ACR20 responses at Week 52 were $61 \%$ and $50 \%$, respectively. Additional efficacy measures are depicted in the Table. The frequency of adverse events (AEs) in the EP is presented in the Table; the majority were mild or moderate in severity. Serious AEs occurred in 15 patients, and one death occurred in the EP population: a myocardial infarction in a PBO/IXE Q2W patient 502 days after starting IXE. 